\title{
The Incidence of Puerperal Metritis in Postpartum Holstein Friesian Dairy Cows
}

\author{
Gavan Constantin*, Riza Mihaela \\ Agriculture Research and Development Station Șimnic, Craiova, Romania \\ Email address: \\ scda_simnic@yahoo.com (G. Constantin) \\ ${ }^{*}$ Corresponding author \\ To cite this article: \\ Gavan Constantin, Riza Mihaela. The Incidence of Puerperal Metritis in Postpartum Holstein Friesian Dairy Cows. Animal and Veterinary \\ Sciences. Vol. 9, No. 5, 2021, pp. 128-133. doi: 10.11648/j.avs.20210905.11
}

Received: August 25, 2021; Accepted: September 10, 2021; Published: September 16, 2021

\begin{abstract}
Puerperal metritis affects dairy cows during the early postpartum (p.p.) period and causes fever, decrease in milk yield, dehydration, reduced rumen fill and activity, and a fetid watery reddish-brown vaginal discharge. The disease is severe and treatment is often required. The objectives of this study were: 1) to evaluate the association among abnormal calving (AC), parity, and season on the incidence of puerperal metritis (PM) during first 14 days p.p.; 2) to describe the rectal temperature (RT) of cows before and offer diagnosis of PM, and 3) to describe associations among PM, and reproductive performance in Holstein Friesian dairy cows. This study Holstein Friesian dairy cows. This study followed a retrospective observational study design in a research dairy herd, after implementation of a health protocol to identify lactating, cows with pp metritis. Cows were classified as cows with normal calving (NC) or abnormal calving (AC), as having PM or not having PM, and according RT at diagnosis: cows with PM without fever, cows with PM and fever and cows without PM. Cows with AC had greater odds of PM than cows with NC. Primiparous cows that calved during the warm season had lower adjusted odds ratio (AOR) of PM than during the cool season. Multiparous cows did not have seasonal effects on PM. There were not detected differences in first - service conception risk or cumulative pregnancy risk by 150 days p.p. between cows with or without PM. In the study the health protocol to identify cows with PM may have resulted in earlier diagnosis and treatment of cows with PM.
\end{abstract}

Keywords: Puerperal Metritis, Rectal Temperature, Health Protocol, Dairy Cows

\section{Introduction}

In postpartum (pp) dairy cows, uterine diseases such as metritis and endometritis affects a large proportion of the cows and are associated with substantial productive loses [1].

Puerperal metritis (PM) has multiple factors contributing to its etiology, severity, and duration [2]. It occurs during the period from calving to when the anterior pituitary gland become responsive to $\mathrm{GnRH}$, approximately 7 to 14 days postpartum [3]. In PM there is an inflammation of all layers of the uterus, and it is characterized by the presence of a fetid, watery, reddish-brown vulvar discharge [4]. Sheldon et al. (2006) [5] standardized the clinical definition of PM to include clinical symptoms such as reduced milk yield, dullness, inapetence or anorexia, evaluated heart rate, apparent dehydration, and fever $\left(>39.5^{\circ} \mathrm{C}\right)$ within the first 21 days p.p. It is generally accepted that up to $40 \%$ of the dairy cows may have clinical metritis within the first two weeks p.p. and infection persist in $10-15 \%$ of animals more than 3 weeks pp causing clinical or subclinical endometritis [6].

Prevention and early treatment of PM may be more economical than allowing the condition to progress.

In dairy herds, protocols and standard Operating Procedures (SOPs) are essential management tools for guiding decisions and criteria used for the diagnosis and treatment of specific health conditions as well as to standardize management practice. Because of the effect of PM on health, early pp identification of cows with PM by monitoring rectal temperature (RT), milk yield (\% drops), udder feel, dehydration, eating/rumination behavior and vaginal discharge and treatment of cows with $\mathrm{PM}$ have suggested [7, 8]. Rectal temperature (RT) is an indicator of core body temperature and is used as diagnostic method to determine if the cow has fever.

Fever is the result of complex communication between the peripheral immune system and the brain in response to 
infection and inflammation, trauma, or both [9].

Fever can be initiated by bacterial lipopolysaccharides (LPS), also known as endotoxin, acting directly as exogenous pyrogens or indirectly by infections that activate liver macrophages [10] to produce endogenous pyrogens (IL-6, IL-1, and tumor necrosis factor- $\alpha$; [11]. Kristula et al., 2001, [12] evaluate p.p. RT and reported that $48 \%$ of cows that calved normally had at least 1 daily RT $>39.1^{\circ} \mathrm{C}$, compared with: $93 \%$ for cows with retained placenta, $83 \%$ for cows with mastitis, $100 \%$ for cows with PM and $78 \%$ for cows with dystocia. They reported that RT alone is not enough to determine if antibiotic treatment is needed for p.p. cows.

The objectives of this study were: 1) to evaluate the association among abnormal calving, parity and season on the incidence of puerperal metritis during first 14 days p.p.; 2) to describe the rectal temperature of cows before and after diagnosis of PM; and 3) to describe associations among PM and reproductive performance in Holstein Friesian dairy cows.

\section{Material and Methods}

\subsection{Cows and Herd Management}

A retrospective study of the incidence and treatment of postpartum metritis (PM) as well as the response and subsequent fertility following therapy was done in the Agricultural Research and Development Station (ARDS) Şimnic - Craiova Dairy herd. Analysis of cow records covered 4 year period from January 2017 through December 2020. The herd consisted of approximately 200 Holstein Friesian cows, and breeding was done by artificial insemination beginning at the first estrus after 50 days postpartum (p.p.).

Prepartum transition cows that were within 3 weeks of calving were maintained on dry lot, fed a low Dietary Cation-Anion Difference (DCAD) diet, and monitored for signs of calving. Calving events such as dystocia, twins, and retained fetal membranes (RFM) were recorded by farm personnel. Dystocia was defined and recorded based on a 5 - point scale as follow: 1) no assistance, 2) slight problem, 3) needed assistance with moderate difficulty for extraction, 4) considerable force used, and 5) extreme difficulty. Cows that did not expel the fetal membranes within 24 hours after calving were considered to have RFM. Cows with dystocia delivered by cesarean section were not included in this study.

After parturition, cows were treated according to standard operational procedures of the farm, which consisted of orally administering $60 \mathrm{~g}$ of $\mathrm{Ca}$ as $\mathrm{CaCl}_{2}$ paste to all multiparous cows and a single intrauterine infusion of $3 \mathrm{~g}$ of oxytetracicline dissolved in $100 \mathrm{ml}$ of sterile water to cows with RFM. At 3-5 days postpartum, healthy cows were moved to a lactating fresh pen kept in an open barn with dry compost and straw bedding. Diets for postpartum (p.p.) transition cows were formulated to meet or exceed the requirements of lactating dairy cows.

The herd was maintained on a daily reproductive herd health program provided by the farm veterinarian. Reproductive management began following a 50 day voluntary waiting period (V.W.P.). All cows were identified in estrus by visual observations. The cows were examined for pregnancy by population per rectum of the uterus and its contents at 42-49 days from last AI. Cows not receiving AI by 84 days p.p. were examined for evidence of cyclicity, and cows with corpus luteum were treated with $25 \mathrm{mg}$ of $\mathrm{PGF}_{2} \alpha$ intramuscularly. Cows were AI at detected estrus. Cows without signs of ovarian activity were treated with $100 \mu \mathrm{g}$ of $\mathrm{GnRH}$ intramuscularly, followed 7 days later with an intramuscular injection of $\mathrm{PGF}_{2} \alpha(25 \mathrm{mg})$ and subsequent $\mathrm{AI}$ at detected estrus. Cows not seen in estrus by 14 days after $\mathrm{PGF}_{2} \alpha$ treatment were reexamined via rectum palpation and treated with $\mathrm{PGF}_{2} \alpha$ only if a corpus luteum was present. Cows that were not inseminated by 120 days p.p. and cows diagnosed not pregnant $>150$ days p.p. were enrolled in the Ovsynch program [13].

Table 1. Identifying cows with puerperal metritis (adapted from Schuenemann, 2016).

\begin{tabular}{llll}
\hline Scores: & $\mathbf{2}$ & $\mathbf{3}$ \\
\hline $\mathbf{0}$ & $\mathbf{2}$ & & $\geq 39.8^{\circ} \mathrm{C}$ \\
\hline $\begin{array}{l}\text { Rectal temperature }\left({ }^{\circ} \mathrm{C}\right): \\
37.7-38.6^{\circ} \mathrm{C}\end{array}$ & $38.7-39.1^{\circ} \mathrm{C}$ & $39.2-39.7^{\circ} \mathrm{C}$ & $>30 \%$ \\
$\begin{array}{l}\text { Milk yield }(\% \text { drop): } \\
<5 \%\end{array}$ & $8-11 \%$ & $15-25 \%$ & $\geq 3$ \\
$\begin{array}{l}\text { Udder fill: } \\
\text { YES }\end{array}$ & & NO & 3 \\
$\begin{array}{l}\text { Dehydration: } \\
\quad\end{array}$ & 1 & 2 & 3 \\
$\begin{array}{l}\text { Eating/Rumination Behavior: } \\
\quad\end{array}$ & 1 & 2 & 3 \\
$\begin{array}{l}\text { Vaginal Discharge: } \\
\quad\end{array}$ & 1 & 2 & $\begin{array}{l}\text { Brown-red watery foul } \\
\text { smelling. }\end{array}$ \\
\hline $\begin{array}{l}\text { No discharge or mucus brown-red } \\
\text { without smell. }\end{array}$ & $\begin{array}{l}\text { Muco-purulent, brown-red without } \\
\text { smell. }\end{array}$ & $\begin{array}{l}\text { Muco-purulent or brown-red watery, } \\
\text { foul smelling. }\end{array}$ \\
\hline
\end{tabular}

Interpretation of metritis scores:

Total score for cows with vaginal score of 2 or 3 :

$\leq 3=$ Normal, $4=$ Watch $/$ Recheck, $\geq 5=$ Sick $/$ Treat . 
Table 2. Dehydration Scores (cited by Schuenemann, 2016 [8]).

\begin{tabular}{|c|c|c|c|c|}
\hline Scores & $\%$ dehydration & Sunken Eye & Skin tent (seconds) & Mucosa (inside the vulva) \\
\hline 0 & $<4$ & No & Normal & Pink/Moist \\
\hline 1 & $4-6$ & Slight recession & 2 to 3 & Pale/Moist \\
\hline 2 & $7-9$ & Yes & 4 to 8 & Pale/Dry \\
\hline 3 & $10-12$ & Yes, eyeballs severely sunken into orbits & $9-12$ & Pale/Dry \\
\hline
\end{tabular}

Interpretation of scores:

$0=$ normal; 1 = watch/recheck; 2 and $3=$ Dehydrated/Treat (fluid therapy)

Table 3. Eating/Rumination behavior Scores (adapted from Schuenmann, 2016 [8]).

\begin{tabular}{lll}
\hline Score & Eating/Rumination & Rumen fill/Activity \\
\hline 0 & Eating/ruminating normal & Yes/Normal 1-2 per miniute \\
1 & Eating/ruminating, but head/ears down & Half fill/activity 1 per minute \\
2 & Off - feed, depressed, head down and drop ears (cold) & No/activity at list 1 in 5 minutes \\
3 & Off - feed, lying, head in lateral position, drop ears (cold) & No/none in 5 minutes \\
\hline
\end{tabular}

Interpretation of scores:

$0=$ normal; $1=$ watch $/$ recheck; 2 and $3=$ sick.

\subsection{Health Protocol to Identify Lactating Dairy Cows with Metritis in Dairy Herd}

A health protocol to Identify Lactating Dairy Cows with puerperal metritis (PM) was implemented beginning January 1, 2016. This postpartum health - monitoring program consisting of daily evaluation of rectal temperature (RT) scores, milk yield (\% drop) scores, udder fill (yes or no), dehydration score, Eating/Rumination behavior scores, and vaginal discharge scores (tables 1, 2, 3), from day 3 to 14 p.p.

All information concerning RT and incidence of PM were stored daily in database.

Cows diagnosed with PM were treated daily for 3 days with ceftiofur $(2.2 \mathrm{mg} / \mathrm{kg}$ intramuscularly) plus supportive therapy (Ca, energy supplements, anti-inflammatory drugs). Cow that did not respond to the 3 days ceftiofur treat meant, but with the persistence of a fetid discharge, received intrauterine infusion of $3 \mathrm{~g}$ of oxytetracicline diluted in sterile water.

Retained fetal membranes (RFM) were recorded in the health records. Collagens therapy results in earlier release of fetal membranes. No attempt at manual removal was made, but the protruding portion was cut off at the base of the udder. Parental antibiotics were administered if there were signs of systemic illness.

\subsection{Data Management}

Data for parity and calving status were recovered from the database and 2 groups of cows were established: cows with normal calving status (NC; cows without calving - related problems) and cows with an abnormal calving status (AC; cows with dystocia, RFM, twins or some combination of these conditions, cows were classified as having PM or not having PM). Cows were classified according RT at diagnosis: cows with $\mathrm{PM}$ without fever (RT $<39.1^{\circ} \mathrm{C}$ ), cows with PM and fever $\left(\mathrm{RT} \geq 39.1^{\circ} \mathrm{C}\right)$ and cows without $\mathrm{PM}$. Cows also were classified as primiparous or multiparous.

Seasons during the study were defined based on the temperature-humidity index. Based on a previous report [14] a temperature-humidity index (THI) cutoff of 76.2 was used to define 2 seasons. A cold season (October to April a mean THI $<76.2$ ), and a warm season (May to September with a mean THI $>76.2$ ).

\subsection{Statistical Analysis}

All outcome variables such as incidence of REM (\%), incidence of PM (\%), first-service conception risk \%, cumulative pregnancy risk by 150 days p.p. (\%) and number of inseminations for pregnant cows were analyzed using logistic regression. The model to analyze incidence of PM included the effects of calving status, parity and season of calving.

Calving-to-first service intervals and calving-to-conception intervals by 150 days p.p. were analyzed with survival analysis.

The models for reproductive outcomes included the main effects of calving status, parity, season at first and PM as explanatory variable. Daily RT for the 5 days before and 5 days after diagnosis of cows with PM was compared with RT of cows without PM [15].

\section{Results and Discussion}

In the 4 year survey period there were 896 parturitions, but 12 cows were not included because they did not complete 11 days of health evaluations. Therefore 884 parturitions were evaluated of which 698 cows $(78.96 \%)$ were classified as NC and 186 cows $(21.04 \%)$ as AC.

\subsection{Disease Incidence}

In the survey period there were 60 cows $(6.79 \%)$ with RFM and 148 cows $(16.74 \%)$ with pm. Of 148 cows diagnosed with PM 92 (62.20\%) were found without fever, and 56 (37.80\%) had fever at diagnosis. Multiparous cows had lower odds for PM than primiparous herd mates (table 4). Cows with AC had higher odds than herd mates with NC (table 4). There was a significant season - by parity interaction. Primiparous cows that calved during the warm season had lower odds of PM than during the cold season (table 4). Multiparous cows did not have a seasonal effect on PM (table 4). 
Table 4. Incidence on risk factors of PM in the first 14 days pp of lactating dairy cows.

\begin{tabular}{|c|c|c|c|c|c|}
\hline \multirow{2}{*}{ Level } & \multicolumn{2}{|c|}{ Incidence of PM } & \multicolumn{3}{|c|}{ Risk of PM } \\
\hline & $\%$ & $\mathbf{n}$ & $\mathbf{A O R}^{1}$ & $95 \% \mathrm{CI}^{2}$ & P. value \\
\hline \multicolumn{6}{|l|}{ PM: } \\
\hline Yes & 16.74 & 148 & - & - & - \\
\hline No & 83.26 & 736 & - & - & - \\
\hline \multicolumn{6}{|l|}{ Parity: } \\
\hline Primiparous & 29.09 & $103 / 354$ & Referent & Referent & 0.06 \\
\hline Multiparous & 38.68 & $205 / 530$ & 0.667 & $0.370-1.126$ & \\
\hline \multicolumn{6}{|c|}{ Calving status: } \\
\hline N.C. & 32.10 & $224 / 698$ & Referent & Referent & 0.08 \\
\hline A.C. & 65.05 & $121 / 186$ & 4.9 & 2.9 to 8.6 & \\
\hline \multicolumn{6}{|c|}{ Parity x Season } \\
\hline \multicolumn{6}{|c|}{ Primiparous: } \\
\hline Cold & 40.00 & $120 / 300$ & Referent & & \\
\hline Warm & 22.22 & $12 / 54$ & 0.26 & 0.08 to 0.64 & \\
\hline \multicolumn{6}{|l|}{ Multiparous: } \\
\hline Cold & 11.50 & $46 / 400$ & Referent & Referent & \\
\hline Warm & 20.00 & $26 / 130$ & 1.53 & 0.62 to 3.18 & \\
\hline
\end{tabular}

$\mathrm{AOR}=$ adjusted odds ratio

$95 \% \mathrm{CI}=95 \%$ confidence interval.

\subsection{RT Measurements}

The mean ( \pm SE), median, upper and lower quartiles and the 95\% CI for RT from day 3 through 14 pp of cows with and without PM are shown in table 5.

Table 5. The mean ( \pm SE) median, upper and lower quartiles and the 95\% CI for RT from day 3 through 14 pp of cows.

\begin{tabular}{llllll}
\hline Cow status & Mean \pm SE & $\mathbf{2 5}^{\text {th }}$ quartile & Median & $\mathbf{7 5}^{\text {th }}$ quartile & $\mathbf{9 5 \%}$ CI \\
\hline NC & $38.5 \pm 0.01$ & 38.2 & 38.4 & 38.8 & 37.7 to 39.4 \\
AC & $38.5 \pm 0.01$ & 38.2 & 38.6 & 39.0 & 37.5 to 39.3 \\
Cows without PM & $38.5 \pm 0.01$ & 38.3 & 38.7 & 38.8 & 37.4 to 39.3 \\
Cows with PM & $38.9 \pm 0.03$ & 38.4 & 38.8 & 39.1 & 37.1 to 40.3 \\
\hline
\end{tabular}

The analysis showed significant interaction between day and PM. Rectal temperature from cows with PM was significantly higher at 72 hours before the diagnosis of PM in cows without PM, and RT continued to be different until day 4 after the diagnosis and treatment of PM (figure 1).

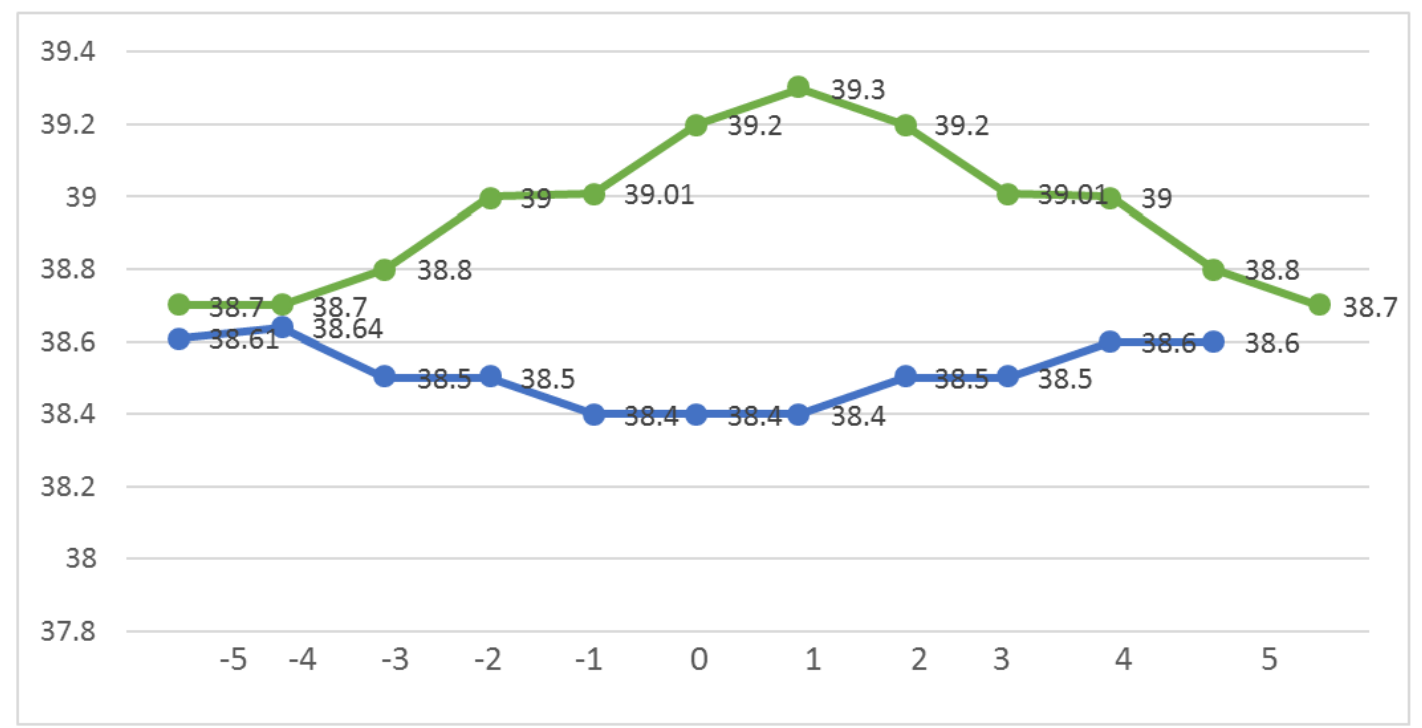

Figure 1. Daily mean $\pm S E$ of $R T$ of cows 5 days before and 5 days after diagnosis of cows with PM (green) and cows without PM (blue).

Rectal temperature in cows diagnosed with PM increased linearly beginning at -2 days before diagnosis of PM and reached a mean $\mathrm{RT}$ of $39.3 \pm 0.06^{\circ} \mathrm{C}$ at day 0 (A difference of $0.9^{\circ} \mathrm{C}$ compared with RT of cows without PM at day 0 ; figure 1). 


\subsection{Reproductive Variables}

There were no differences detected in first-service conception risk and accumulated pregnant risk by 150 days p.p. for calving status, parity, and PM (not showed). No differences were observed on hazard of calving to first service intervals and calving-to-conception intervals by 150 days p.p. for cows with or without PM (table 5).

Cows with PM had $8.2 \%$ more inseminations per pregnancy than cows without PM. This difference was no significant.

Table 6. Proportional hazards regression model of calving-to-first service intervals and calving-to-conception intervals by 150 days p.p. by calving status, parties, season, and presence or absence of PM.

\begin{tabular}{|c|c|c|c|c|c|c|c|c|}
\hline \multirow{2}{*}{ Level } & \multicolumn{4}{|c|}{ Calving-to-first service } & \multicolumn{4}{|c|}{ Calving-to-conception by 150 days p.p. } \\
\hline & Median \pm SE & Hazard & $95 \%$ CI & P. value & Median \pm SE & Hazard & $95 \%$ CI & P. value \\
\hline \multicolumn{9}{|c|}{ Calving status: } \\
\hline $\mathrm{NC}$ & $68.0 \pm 1.8$ & \multirow{2}{*}{0.86} & Referent & \multirow{2}{*}{0.4} & $128.0 \pm 2.2$ & \multirow{3}{*}{1.02} & Referent & \multirow[t]{2}{*}{0.9} \\
\hline $\mathrm{AC}$ & $72.0 \pm 3.1$ & & 0.64 to 1.00 & & $134.2 \pm 3.2$ & & 0.8 to 1.28 & \\
\hline \multicolumn{8}{|l|}{ PM: } & \\
\hline No & $69.2 \pm 1.7$ & \multirow{3}{*}{0.95} & Referent & \multirow{3}{*}{0.8} & $126.0 \pm 2.3$ & \multirow{3}{*}{0.98} & Referent & \multirow[t]{2}{*}{0.8} \\
\hline Yes & $78.4 \pm 3.6$ & & 0.70 to 1.24 & & $151.0 \pm 3.7$ & & 0.72 to 1.26 & \\
\hline \multicolumn{6}{|l|}{ Parity: } & & & \\
\hline Multiparous & $71.0 \pm 2.2$ & \multirow{3}{*}{1.37} & \multirow{2}{*}{\multicolumn{2}{|c|}{$\begin{array}{l}\text { Referent } \\
1.20 \text { to } 1.71\end{array}$}} & $130.0 \pm 2.4$ & \multirow{3}{*}{0.96} & Referent & \multirow[t]{2}{*}{0.7} \\
\hline Primiparous & $67.8 \pm 2.2$ & & & & $125.0 \pm 2.8$ & & 0.79 to 1.20 & \\
\hline \multicolumn{7}{|l|}{ Season: } & & \\
\hline Cold & $68.0 \pm 1.8$ & \multirow{2}{*}{0.72} & \multirow{2}{*}{\multicolumn{2}{|c|}{$\begin{array}{l}\text { Referent } \\
0.58 \text { to } 0.92\end{array}$}} & $120.0 \pm 2.0$ & \multirow{2}{*}{0.94} & Referent & \multirow[t]{2}{*}{0.098} \\
\hline Warm & $82.2 \pm 4.2$ & & & & $129.0 \pm 3.2$ & & 0.74 to 1.22 & \\
\hline
\end{tabular}

Cows with dystocia, RFM, twins or same combination of this conditions had an AC.

Primiparous cows in this study had a higher incidence of PM during the cold season. Effects of season and parity on incidence of PM have been described previously by Markusfeld [16], 1984, Smith et al. [17], 1998, Benzaquen et al. [2], 2006.

Normal RT have been reported within the range of 38.0 to $39.1^{\circ} \mathrm{C}[18]$ and cows with RT above $39.1^{\circ} \mathrm{C}$ were defined as febrile. Benzaquen et al., 2006 [2], reported a mean RT of $38.6^{\circ} \mathrm{C}$ for cows without PM. In the present study the mean RT of $38.5^{\circ} \mathrm{C}$ for cows without PM was in agreement with that reported by Kristula et al. [12], 2001, Sheldon et al. [6], 2004 and Benzaquen et al. [2], 2006.

Daily increases of RT before diagnosis of PM was reported by Benzaquen et al. [2], 2006. In the present study RT of cows with PM started increasing 2 days before the diagnosis of PM and did not reach a predefined febrile level of $39.4^{\circ} \mathrm{C}$ $[7,2]$, due to the proportion of cows with PM on day 0 that did not have a fever.

Benzaquen et al. [2], 2006, suggested that the classical definition of fever $\left(39.4^{\circ} \mathrm{C}\right)$ is not appropriate for diagnosis of metritis that includes clinical symptoms.

Sheldon et al. [19], 2004, used a cut-off point to define the categories of pyrexia and normal RT was set as the $75^{\text {th }}$ quartile of the maximum RT, and they found that this $75^{\text {th }}$ quartile of m maximal RT recorded a 10 days p.p. period for normal and RFM cows was equal to $39.7^{\circ} \mathrm{C}$.

Benzaquen et al. [2], 2006, utilizing a more conservative approach with 356 cows that did not develop PM on using all daily temperature for 13 days period, the $75^{\text {th }}$ quartile in their study was $38.8^{\circ} \mathrm{C}$. In this study the $75^{\text {th }}$ quartile was also of $38.8^{\circ} \mathrm{C}$. Consequently a RT of $>38.8^{\circ} \mathrm{C}$ could be considered as a potential RT warranting further clinical evaluation for PM [2].

Abnormal calving or PM did not have a significant effect on reproductive performance. Fourichon et al. [1], 2000, showed less effects of PM in studies reporting routine examination of cows compared with herds in which the owner reported the disease. Results of the present study show the classical effects of seasonal heat stress on fertility.

\section{Conclusions}

In the present study the health protocol to identify Lactating dairy cows with metritis may have resulted in an earlier diagnosis and treatment of PM.

Cows with AC had greater odds of PM than those with NC status. Evaluation of daily RT distinguished cows with PM with or without fever. A higher proportion of cows did not have fever at the time PM was diagnosed.

Diagnostic and treatment consideration for PM should include the attitude of the cow and the condition of the uterus and not RT alone.

In cows diagnosed with PM and treated, first-service conception risk and cumulative pregnancy-risk by 150 days p.p. were comparable to cows with $\mathrm{NC}$ or $\mathrm{AC}$ status the not experience PM.

\section{References}

[1] Fourichon, C., H. Seegers and X. Malher, 2000. Effect of disease on reproduction in the dairy cows: A meta-analysis. Theriogenology 53: 1729-1759.

[2] Benzaquen, M. E., C. A. Risco, L. F. Archbald, M-J. Thatcher and W. W. Thatcher, 2006. Rectal temperature, CalvingRelated Factors ant the incidence of Puerperal Metritis in Postpartum Dairy Cows.

[3] Olson J. D., K. N. Bretzloff, R. G. Mortimer, and L. Ball, 1986. The metritis pyometra complex. Pages 227-236 in Current Therapy in Theriogenology 2: Diagnosis, Treatment and Prevention of Reproductive performance in Holstein cows. J. Dairy Sci. 66: 612-619. 
[4] Lewis G. S. 1997. Uterine health and disorders. J. Dairy Sci. 80: 984-994.

[5] Sheldon I. M., G. S. Lewis, S. Leblanc, and R. O. Gilbert, 2006 Defining postpartum uterine disease in cattle. Theriogenology 65: $1516-1530$.

[6] Sheldon I. M., G. S. Lewis, 2004. Postpartum uterine health in cattle. Anim. Reprod. Sci. 82: 295-306.

[7] Upham G. L. 1996. A practitioner's approach to management of metritis/endometritis: Early detection and supportive treatment. Proc. $29^{\text {th }}$ Anim. Conv. Am. Assoc. Bovine. Pract. San Diego. Ca Frontier Printers inc. Stillwater, OK.

[8] Schuenemann G. M., 2016. Protocol: Identifying Lactating Dairy Cows with metritis. https://vet.osu.edu/sites/vet.osu.edu./files/documents.

[9] Leon R. L. 2002. Invited review: Cytokine regulation of fever: studies using gene knockout mice. J. Appl. Physiol. 92: 2648-2655.

[10] Steiner A. A., S. Schakravarty, A. Y. Rudaya, M. Herkenham, and A. A. Romanovsky, 2006. Bacterial lipopolysaccharide fever is initiated via Toll-like receptor 4 on hematopoietic cells. Blood 107: 4000-4002.

[11] Mackowiak P. A., J. G. Bartlett, E. C. Borden, S. E. Goldblum, J. D. Hasday, R. S. Munford, S. A. Nasraway, P. D. Stolley, and T. E. Woodward, 1997. Concept of fever: Recent advances and lingering dogma. Clin. Infect. Dis. 25: 119-138.
[12] Kristula, M., B. I. Smith, and A. Simeone. 2001. The use of daily postpartum rectal temperature to select dairy cows for treatment with systemic antibiotics. Bovine Pract. 35: 117-125.

[13] J. R. Pursley, M. O. Mee, M. C. Wiltbank, 1995, Synchronization of ovulation in dairy cows using $\mathrm{PGF}_{2} \alpha$ and GnRH, Theriogenology, Volume 44, Issue 7, Pages 915-923.

[14] Miller R. F., Svejcar T. J., West N. E., 1994, Implication of livestock grazing in the intermountain sage brush region: plant composition, Ecological implication of herbivory in the west, pp 101-146., ref. 298.

[15] M. E. Benzaquen, C. A. Risco, L. F. Archbald, P. Melendez, M.-J. Thatcher, W. W. Thatcher, 2007, Rectal temperature, calving-related factors, and the incidence of puerperal metritis in postpartum dairy cows, Journal of Dairy Science, Volume 90, Issue 6, Pages 2804-2814.

[16] Markusfeld O., 1984. Factors responsible for postparturient metritis in dairy cattle. Vet. Rec. 114: 539-542.

[17] Smith B. I., G. A. Donovan, C. A. Risco, R. Littell, C. Young, L. H. Stanker, and J. Elliot, 1998. Comparison of various antibiotic treatment for cows diagnosed with toxic puerperal metritis. J. Dairy Sci. 81: 1555-1562.

[18] Rebhun, W. C.; Guard, C.; Richards, C. M., 1995, Diseases of dairy cattle, agris.fao.org, Publisher: Williams and Wilkins. ISBN: 06-830-71939.

[19] Sheldon I. M., A. N. Rycroft, and C. Zhan, 2004. Association between postpartum pyrexia and uterine bacterial infection in dairy cattle. Vet. Rec. 154: 289-293. 